\title{
O NOVO DISCURSO DO CAPITAL
}

\section{Ariovaldo de Oliveira Santos}

O presente artigo procura demarcar certos traços que atravessam atualmente as proposições neoliberais ou que buscam nos pressupostos do neoliberalismo uma fonte de inspiração. Certamente, não se trata de estudo nem exaustivo nem definitivo. A primeira dimensão estando ausente das possibilidades contidas em um curto artigo e a segunda impossível de ser ainda totalmente dimensionada, muito embora traços de suas consequiências futuras sejam evidentes, principalmente junto ao mundo do trabalho.

Palavras-Chave: Neoliberalismo; Crise do Capitalismo

\section{A NOVA CRISE DO CAPITAL}

$\mathrm{E}$ m livro publicado no final dos anos 70 , Granou, Baron e Billaudot observam: "crise é um périodo de instabilidade $e$ de incerteza onde o capitalismo deve se autoquestionar, mas também é um momento onde ele constrói progressivamente suas soluções» '.

Quando consideramos o processo de desenvolvimento do modo de produção capitalista ao longo dos últimos 150 anos, a passagem citada se revela, à primeira vista, plenamente verdadeira. Afinal, apesar de certas iniciativas de caráter revolucionário, a classe operária não liquidou com o capital e suas tentativas mais radicais para fazê-lo revelaram sempre um descompasso entre as condições subjetivas e objetivas do processo de transformação social. Tragédia vivida, por exemplo, no século XIX, por ocasião das jornadas revolucionárias de 1848-1849 e repetida, no século

1 - Granou, André; Baron, Yves; Billaudot, Bernard, Croissance et Crise, Maspero, Paris, 1979, p.248.
XX, pela Revolução Russa e outras tentativas de instauração do comunismo no leste europeu.

Juntos, os dois séculos demonstraram que é necessário mais do que o voluntarismo (elemento sempre combatido por Marx, Engels e os clássicos do marxismo) para suplantar o modo de produção capitalista. Questão que se confirma plenamente quando observado que as crises, uma das condições essenciais para que o processo de destruição do capital possa ser colocado em marcha, não cessaram de se reproduzir periodicamente desde a constituição do modo de produção capitalista. A mais recente destas crises, iniciada nos anos 1970 e atingindo conjuntamente a maior parte dos países do capitalismo industrializado, mostra não somente a freqüência com a qual o fenômeno se repete mas, também, a vitalidade do capital em esboçar soluções aos seus problemas mais imediatos de acumulação $\mathrm{e}$ reprodução de suas estruturas.

No entanto, uma análise mais fina deste desenvolvimento, marcado por crescimentos e crises, revela a parcialidade da afirmação que abre este artigo. Parcialidade que se acentua à medida em que ela, assim como todo o livro, não avança em direção 
a uma outra dimensão que atravessa esta dialética de crescimento e crise. Por outras palavras, é certo que até o momento este processo esteve sempre acompanhado pela elaboração de certas respostas que transcendem a realização de dois conflitos mundiais ou a repressão pura e simples do mundo do trabalho por regimes fascistas, ditatoriais, liberais ou de não importa qual gênero. A busca de respostas conduziu mesmo a iniciativas centradas em pactos envolvendo sindicatos, patronato e o Estado, como é o caso para os Estados Unidos, Japão, Europa Ocidental e mais timidamente em alguns países da América Latina, como é o caso do Brasil. Pactos que diferem em sua construção mas cuja arquitetura, sob o manto de redistribuição de alguns benefícios à população, não tem outro fim que o de manter a exploração e a acumulação de capital em níveis elevados ou aceitáveis.

Neste sentido, o pacto social-democrata, construído na Europa Ocidental após o fim da Segunda Grande Guerra se revela exemplar. Lipietz observa que a "política econômica socialdemocrata no sentido amplo do termo, repousava sobre a idéia de que o fordismo era benéfico a todo mundo [...] o progresso social decorreria do progresso técnico. $O$ primeiro sendo um subproduto do segundo. O Estado intervinha para corrigir os excessos e as insuficiências das leis de mercado e, sobretudo, ele organizava e favorecia $o$ diálogo e o compromisso entre as forças sociais» de tal maneira que "a relação de forças permanecesse equilibrada». De fato, no interior do equilíbrio fordista "as empresas têm mais interesse em aumentar regularmente os salários, em particular dentro do quadro das convenções coletivas, do que em arriscar um enfrentamento $e$, coletivamente, uma alta insuficiente de seus mercados. $E$ os assalariados, eles também, têm interesse em reivindicar coletivamente altas de salários mas não mais rápidas que os ganhos de produtividade». Por seu lado, «os Estado arbitra» (Lipietz, A, 1985 p. 93 à 94).

No entanto, estas respostas, por mais duradouras que sejam, nem suprimiram ou suprimem os conflitos entre as classes, nem eliminam as crises, mas colocam a ambos em um outro patamar de desenvolvimento. Assim, o esgotamento dos pactos do pós-guerra marca também o mergulho do capital na mais longa e profunda crise de toda sua história. Considerada no início, pelo discurso dominante à época, como uma simples recessão, a crise é admitida posteriormente como sendo um fenômeno cuja duração seria bastante limitada. No entanto, apesar das expectativas favoráveis, a crise se instaura em profundidade nos anos 70 junto às economias dos países capitalistas desenvolvidos, se radicaliza nos anos 80 e continua sua marcha destruidora nos anos 1990.

As possibilidades de se transcender a atual crise são de tal ordem que, para responder à realidade do desemprego, do crescimento, da exclusão social, o próprio discurso deve se auto-reformular e encontrar uma nova legitimação junto aos diversos setores que compõem cada sociedade que possamos considerar. Tarefa pressentida como sendo de urgência pois se existe algo de evidente ao longo destes 25 anos de crise do capitalismo nos países do capitalismo avançado, isto se refere à insuficiência dos remédios tentados por liberais, socialistas ou socialdemocratas. Cada um à sua maneira ensaiaram um caminho e, ao mesmo tempo, cada um contribuiu a explicitar a permanência de tentativas frustradas por parte do capital para resolver seus problemas mais vitais.

Desse modo, à constatação de que o capital sempre encontrou alternativas às suas crises é necessário acrescentar um outro dado: é certo que o capitalismo alterna períodos de crescimento com outros de crise. No entanto, é certo também que a cada uma destas fases as crises se revelam mais profundas e mais difíceis de serem equacionadas. Os resultados colhidos pelas várias políticas econômicas implementadas ao longo de mais de vinte anos nos países de economia capitalista avançada nada mais fazem do que reforçar esta afirmação. Os chamados Trinta Gloriosos são cada vez mais lembrados como um período de exceção na história do desenvolvimento dos países do capitalismo avançado. Com isto se pretende de certa forma justificar a impotência dos remédios tentados para resolver a crise. Ao mesmo tempo, tratar os Trinta Gloriosos como período de exceção e com um certo saudosismo contribui a legitimar a presença de uma situação marcada por elevado nível de desemprego em contraposição à anterior, considerada como sendo de pleno emprego. A progressiva substituição do keynesianismo do pós-guerra pelos ideais antisociais da Escola de Chicago nada mais faz do que alimentar a idéia dos Trinta Gloriosos como 
exceção e não como regra. Reflexão que, no limite, aponta para a impossibilidade do movimento de produção e reprodução do capital de fornecer um tipo de desenvolvimento social aceitável às grandes massas que compõem a população de cada país considerado. Principalmente se a solução proposta é a contida no receituário neoliberal.

\section{UM DISCURSO QUE SE TRANSFORMA}

O neoliberalismo constitui, nestes tempos de crise, um dos patrimônios mais preciosos do qual dispõe o capital. De um lado, em razão de que ele se apresenta como uma forma de explicação para a crise. Fato para o qual contribui o desmoronamento do leste europeu e suas conseqüências junto às diversas frações da esquerda comunista e socialista. Por outro lado, ainda que criticado, certos pontos do projeto neoliberal estão longe de serem profundamente recusados pela nova esquerda, principalmente por aquela mais identificada à socialdemocracia. Disto constituem um exemplo a crítica parcial que elas fazem às privatizações, a aceitação parcial do discurso sobre a necessidade de um rigor orçamentário por parte do Estado, assim como uma certa incorporação do discurso oficial sobre os instrumentos a serem adotados para se controlar a inflação.

No entanto, mais do que um projeto assentado em certos princípios vendidos como receitas mágicas a quem estiver disposto a pagar o preço, falar em neoliberalismo implica também se referir a um discurso que se transforma. $\mathrm{E}$ isto tanto mais à medida em que os resultados recolhidos se revelam cada vez mais distantes das soluções inicialmente pretendidas. As respostas apresentadas aos problemas vividos pelo mundo do trabalho se revelam, neste sentido, bastante exemplares e a elas dedicamos nossa atenção nesta segunda parte de nosso artigo.

Um primeiro argumento se faz em torno de uma suposta correlação automática entre crescimentoemprego. Assim, restabelecer o crescimento econômico se apresenta, em um primeiro momento, como condição sine qua non para a recuperação das contas públicas, ao mesmo tempo que para o restabelecimento da situação de pleno emprego existente no período anterior à crise, isto é, o período dos Trinta Gloriosos.

Este discurso sofre no entanto uma forte inflexão nos anos 1990 e cada vez mais seu eixo de análise se afasta da idéia de uma correlação imediata entre crescimento-emprego-saúde financeira do Estado. A necessidade de se restabelecer o crescimento continua como preocupação essencial. No entanto, progressivamente, o eixo da reflexão é de que mesmo um forte período de crescimento econômico seria insuficiente para restabelecer as condições favoráveis existentes dos Trinta Gloriosos , principalmente no que se refere às possibilidades de restabelecimento do pleno emprego - A própria idéia de pleno emprego não está isenta de modificações com objetivo de melhor legitimar uma determinada situação de degradação social. Assim, em recente livro Rifkin observa: «Com a porcentagem de desempregados aumentando progressivamente durante o período do pós-guerra, os economistas modificaram sua definição de pleno emprego. Nos anos cinqüenta, um desemprego de 3 $\%$ era, para a maioria, sinônimo de pleno emprego. A partir dos anos sessenta, a administração Keneddy e Johnson proclamavam que $4 \%$ de desemprego correspondia ao objetivo do pleno emprego. Nos anos oitenta, a ortodoxia econômica viu o quase pleno emprego na taxa de 5 $\%$ ou mesmo 5,5\% de desemprego. Hoje, chegados à metade dos anos noventa, cada vez mais os economistas e os dirigentes de empresa revisam seus pontos de vista sobre o 'nível natural' de desemprego. Completamente hesitando em falar de 'pleno emprego' numerosos analistas de Wall Street afirmam que os níveis de desemprego não deveriam descer abaixo de $6 \%$, sob pena de ver a economia caminhar em direção a um novo período de inflação» ${ }^{2}$

Longe de constituir um monopólio do militantes da causa neoliberal, este eixo de raciocínio encontra um número cada vez maior de adeptos. Assim, diz por exemplo Morin: «Enquanto que o progresso técnico, crescimento econômico e pleno emprego andaram durante muito tempo de mãos dada», outra é hoje a situação, pois "este mecanismo não atua mais [...] o progresso técnico atual provoca mais repercussões sobre os processos de

\footnotetext{
2 - Rifkin, Jeremy, La Fin du Travail, La Découverte, Paris,
} 1996, p. 30 à 31. 
fabricação (automatização, informática, robôs, máquinas pilotadas por computadores, etc...) ao mesmo tempo em que se faz acompanhar de um decréscimo forte de certos empregos sem que o terceário possa compensar com empregos equivalentes, seja em número, seja em qualidade» 3 .

As transformações do discurso são evidentes também no que se refere ao tratamento do desemprego. Fato que se acentua à medida em que este se agrava ao longo dos anos 1980 e 1990, sobretudo junto aos jovens, às mulheres, às pessoas de meia idade e àqueles sem qualificação profissional. De fato, o argumento estabelecendo a correlação crescimento-emprego é, ao mesmo tempo, a recusa à situação de desemprego, cada vez mais durável, que atinge os diversos países do capitalismo desenvolvido desde o início da crise, em 1973. De situação inaceitável se transita em direção a uma posição mais flexível, isto é, a aceitação do desemprego de massa e de longa duração como consequiência de um processo de transição das diversas economias. Transição inscrita nos quadros do processo de globalização e abertura das fronteiras. Desta posição se avança a uma outra, bem menos otimista mas considerada, de qualquer modo, como mais realista. Assim, para Brunhes Consultores, por exemplo, o desemprego «não é o resultado aritmético de uma baixa da produção; ele não é - ou não é somente - um fenômeno conjuntural que a retomada econômica fará desaparecer. Na realidade, ele é a conseqüência de uma inadaptação crescente entre a busca de trabalho por parte das empresas e a oferta de trabalhadores. Ele traduz a dificuldade que reencontram as sociedades européias para fazer evoluir seus modos de organização, de regulação econômica e social em direção a uma nova situação tecnológica e a uma nova divisão internacional do trabalho [...] As grandes empresas foram durante muito tempo a fonte de criação de empregos. Não é mais o caso hoje [...] Tudo isto foi varrido» pela «flexibilização, polivalência, individualização, descentralização de iniciativa e de responsabilidades» ${ }^{4}$.

\footnotetext{
3 - Morin, Pierre, La Grande Mutation du Travail et de l'Emploi, Paris, Les Editions de l'Organisation, 1994, p. 33.

4 - Kaisergruber, Danielle, L'Europe de l'emploi ou comment font les autres, Les Editions de l'Organisation, Paris, 1994, p. 13.
}

Para além de sua permanente transformação a fim de poder se legitimar face a uma realidade cada vez mais excludente, o discurso liberal avançou, nos anos 1990, em direção a dois outros pontos que permitem dizer que ele é ao mesmo tempo um discurso que desilude as grandes massas ao mesmo tempo em que as culpabiliza pela situação na qual se encontram. Neste sentido, é vendida cada vez mais a idéia de que o futuro, diferentemente dos Trinta Gloriosos, será sem pleno emprego e, pior ainda, os empregos que existirem não serão estáveis. Por outras palavras, está terminada a época em que uma pessoa possuía todas as expectativas e mesmo possibilidades de atravessar toda uma vida em uma mesma empresa, galgando progressivamente os postos por ela oferecidos. Tudo isto pertence, segundo esta ordem de raciocínio, à sociedade industrial, momento no qual as economias não eram ainda fortemente interdependentes. Outra é a situação atual. A globalização das economias, a introdução de novas tecnologias nas indústrias e nos escritórios, as exigências de flexibilidade do trabalho impostas pela nova situação não apenas lançaram as bases da sociedade pós-industrial mas também destruíram a lógica anteriormente reinante de um emprego, uma vida ${ }^{5}$.

Garantir a aceitação desta idéia se apresenta, ao mesmo tempo, como condição imprescindível à generalização de uma outra relação entre o capital e o trabalho. Mais precisamente, a generalização de formas precárias de emprego. Afinal, o que é oferecido em troca dos hoje considerados «antigos» contratos a duração indeterminada (CDI) ? Nada mais do que seu oposto, isto é, os contratos a duração determinada (CDD), aos quais se acrescentam outras diversas formas de precarização, tais como a reinvenção do trabalho domiciliar, favorecido sobretudo pela forte impulsão, nos últimos anos, da telemática.

Neste sentido, não se trata apenas da generalização de empregos menos estáveis, o que em si já representaria um problema. Está em pauta também é o fato de que os empregos desaparecem ao mesmo tempo em que os que permanecem são cada vez mais precarizados. Ao trabalho em migalhas, analisado por Friedman, vem se ajuntar o emprego em migalhas sob uma multiplicidade de formas.

5 - Morin, Pierre, La grande mutation du travail et de l'emploi, Les Editions de l'Organisation, Paris, 1994. 
Enquanto que no pós-guerra o que predomina são os CDI, o novo discurso da ordem se vê obrigado a admitir que, futuramente, vão dominar os CDD.

A este discurso que desilude o mundo do trabalho e busca the preparar para a nova realidade, como caminho inexorável e do qual não se pode escapar, se acrescentam os esforços para encontrar um culpado ao desemprego de massa. E, neste sentido, cada vez mais a força-de-trabalho ou o exército industrial de reserva é culpabilizado. Por outras palavras, confrontada de um lado a um crescimento que não é mais gerador de empregos como anteriormente e, de outro, a um mercado de trabalho fragmentado de múltiplas formas, tanto a força de trabalho em atividade quanto aquela que integra o cada vez mais numeroso exército industrial de reserva, são convocados a fazer o mea culpa.

Outro não é o sentido do atual discurso sobre «empregabilidade». Em recente encontro realizado na França entre a Associação para Facilitar a Inserção dos Jovens Diplomados e representantes da nova geração do patronato, foi lançado o seguinte argumento por parte de um dos representantes empresariais: "Nós temos o dever de dizer aos jovens que no futuro o diploma terá cada vez menos valor [...] A abordagem tradicional diploma-emprego está superada». Doravante, o que predominará será a relação «competência-emprego» 6 .

As afirmações não deixam dúvidas. Até período bastante recente, a conquista de um diploma era vivida como o caminho mais seguro para escapar às penúrias do desemprego. Desmascarado pela dura realidade, este discurso é transformado pela incorporação obrigatória de novos elementos, dos quais a competência individual é erigida a primeiro plano. Em resumo, transformado em espaço de luta acirrada de todos contra todos na busca de um emprego, o mercado de trabalho se apresenta ao capital como o espaço de realização de um novo darwinismo, expresso pela lógica de que, doravante, somente os mais aptos sobreviverão.

\section{CONCLUSÃO}

Embora breves, os elementos anteriormente apresentados se revelam significativos para uma apreensão das dificuldades vividas atualmente pelo capital em seus esforços para garantir sua produção e reprodução ampliada. Eles indicam ao mesmo tempo as dificuldades do capital em fornecer, mesmo que a nível provisório, uma solução minimamente aceitável para as grandes massas da população de cada país. Dificuldades que não se revelam mais profundas em grande parte em razão do refluxo sofrido nos últimos anos pelo mundo do trabalho em seus embates cotidianos. De todo modo, estas pequenas fissuras indicam que não se chegou nem ao fim da história e que nem a partida está terminada. $O$ resultado, somente o embate entre as classe poderá definir.

\section{REFERÊNCIAS BIBLIOGRÁFICAS}

ANDRE, Cathérine \& SICOT, Dominique, Le Chômage dans

les Pays Industrialisés, Syros, Paris, 1994, 126 p.

ATKINSON, Anthony, Pour l'Emploi et la Cohésion Sociale, Presses de la Fondation Nationale des Sciences Politiques,

Paris, 1994, 238 p.

CHANARON \& J-J et LUNG, Yannick, Economie de

l'Automobile, La Découverte, Paris, 1995, 125 p.

CORIAT, Benjamin et TADDEI, Dominique, Made in

France, Librairie Générale Française, Paris, 1993, 471 p.

GRANOU, André; Baron, Yves \& Billaudot, Bernard, Croissance et Crise, Masdpero, Paris, 1979, 253 p.

RIF KIN, Jeremy, La Fin du Travail, La Découverte, Paris, 1996, 435 p.

HELLIER, J. \& REDOR, D, Le Travail en Europe Aujourd'hui et Demain, Masson, Paris, 1992, 228 p.

KAISERGRUBER, Danielle, L'Europe de l'Emploi, Les

Editions de l'Organisation, Paris, 1994, 296 p.

LEBAUBE, Alain, L'Emploi en Miettes, Hachette, Paris, $1988,258 \mathrm{p}$.

LIPIETZ, Alain \& Clerc, Denis, La Crise, Syros, Paris, 1983, $152 \mathrm{p}$.

MANDEL, Ernest, La Crise, Flammarion, Paris, 1985, 352 p.

MARCEL, Bruno \& TAIEB, Jacques, Crises d'Hier Crise

d'Aujourd'hui, Nathan, Paris, 1992, 255 p.

MARCEL, Bruno \& TAÏEB, Jacques, Le Chômage Aujourd'hui (un phenomène pluriel), Nathan, Paris, 1991, $207 \mathrm{p}$.

MAZEL, Olivier, Les Chômages, Marabout, Paris, 1993, 180 p.

MORIN, Pierre, La Grande Mutation du Travail et de l'Emploi, Les Editions d'Organisation, Paris, 1994, 167 p.

PAYSANT, Michel et BATTY, Fabrice, Travail Salarié, Travail Indépendent, Dominos/Flammarion, Paris, 1995, $126 \mathrm{p}$.

SPITAELS, Guy, Les Conflits Sociaux en Europe, Marabout, Belgique, $1971,320 \mathrm{p}$.

\footnotetext{
6 - Penicaut, Nicole, Diplômés, encore un petit effort, in
} Libération, 4 décembre 1995, p. 24. 